\title{
The association between parental migration and early childhood nutrition of left-behind children in rural China
}

\author{
Huifeng Shi' ${ }^{1}$ Jingxu Zhang ${ }^{1}$, Yufeng Du' ${ }^{1}$ Chunxia Zhao ${ }^{2}$, Xiaona Huang ${ }^{2}$ and Xiaoli Wang ${ }^{1 *}$
}

\begin{abstract}
Background: More than one-third of children under 3 years old are left behind at home due to parental migration in rural China, and we know very little about early childhood nutrition of left-behind children (LBC) because of the dearth of research. This study examined the association between parental migration and early childhood nutrition of LBC in rural China.
\end{abstract}

Methods: We used repeated cross-sectional data of rural children aged 6-35 months who participated in two surveys in six counties of northern and southern China in 2013 and 2016 respectively. The length, weight, and hemoglobin concentration were measured by trained health-care workers blinded to parental migration status. Stunting, underweight, wasting, and anemia were identified with the standards recommended by WHO. Generalized linear regressions and multivariate logistic regressions were employed to explore the association between parental migration and these nutritional outcomes at each time point.

Results: Two thousand three hundred thirty-six and 2210 children aged 6-35 months were enrolled in 2013 and 2016, respectively. The results show a reduction of the risks of stunting, underweight, and wasting from 2013 (16.4, 8.5 , and 3.5\%, respectively) to $2016(12.1,4.0$, and $1.5 \%$, respectively) but highlight a constantly and alarmingly high risk of anemia among these children (44.8\% in 2013 and 43.8\% in 2016). Children with migrant fathers performed as well as or better than those with non-migrants on these indicators. Children with migrant parents performed slightly worse in 2013, but equal or slightly superior in 2016 on these indicators compared with children with nonmigrants and migrant fathers. Children aged 6-17 months with migrant parents had a significantly lower risk of anemia than those living with their mothers or with both parents $(43.1 \%$ vs. $63.6 \%$ and 61.5 in 2013 , and 42.5 vs. 60.1 and $66.2 \%$ in 2016), even after controlling for children's sociodemographic characteristics.

Conclusions: Parental migration may be not detrimental and even beneficial to early childhood nutrition of LBC in rural China. Continued nutritional support is needed for all rural children, especially interventions for preventing micronutrient deficiency. Programs for $L B C$ are recommended to continue to focus on nutrition but pay more attention to other important health issues.

Keywords: Parental migration, Left-behind children, Early childhood, Undernutrition, Anemia, Rural China

\footnotetext{
* Correspondence: xlwang@bjmu.edu.cn

'Department of Maternal and Child Health, School of Public Health, Peking

University, 38 Xueyuan Road, Haidian District, Beijing 100191, China

Full list of author information is available at the end of the article
}

(c) The Author(s). 2020 Open Access This article is distributed under the terms of the Creative Commons Attribution 4.0 International License (http://creativecommons.org/licenses/by/4.0/), which permits unrestricted use, distribution, and reproduction in any medium, provided you give appropriate credit to the original author(s) and the source, provide a link to the Creative Commons license, and indicate if changes were made. The Creative Commons Public Domain Dedication waiver (http://creativecommons.org/publicdomain/zero/1.0/) applies to the data made available in this article, unless otherwise stated. 


\section{Background}

There are about 1 billion migrants globally [1]. In China, since the reform and opening-up in the 1980s, a large number of rural residents have migrated from their homes to cities in search of better employment opportunities. However, because of the unstable income, unfriendly settlement policies, and limited access to public services (such as education and health care) in host cities, most labor migrants leave their children at their homes in the countryside with another parent or other family members. According to the latest statistics, in 2015, 40.51 million rural children were left behind due to parental migration, accounting for $29.4 \%$ of all rural children and 15\% of all children in China [2].

The nutritional status of left-behind children, as one of their most important health outcomes, has drawn a lot of attention from researchers and policy-makers. A growing body of research in this field over the last three decades has yielded conflicting results. Most studies found that leftbehind children were more likely to be stunted, underweight, or wasted compared with other children [3-11], but others found that left-behind children performed similarly to, or even better than, non-left-behind children on these anthropometric indicators [12-15]. In addition, some studies identified a higher risk of anemia among left-behind than non-left-behind children [16, 17], but other work found no such difference [14]. A recent systematic review and metaanalysis of these studies done from 1994 to September 2018, $82 \%$ of which were conducted in China, found that, compared with non-left-behind children, left-behind children had a significantly increased risk of wasting and stunting, but a similar risk of underweight and anemia [18].

Further research is necessary for consideration of the confusing findings and the possible shift in the impact of parental migration on child nutrition with socioeconomic development. In addition, despite numerous studies existing, some notable gaps in our knowledge remain. Firstly, most studies on nutrition of left-behind children focused on school-age children and few included infants and young children [18]. The findings from school-age children cannot be simply generalized to younger children because of the considerable differences in growth trajectories and living environment. Studies have provided strong evidence that undernutrition in the first 3 years of life has a long-term negative effect on an individual's health and development in subsequent childhood and adulthood, and intervention is problematic once this window has passed [19-21]. Therefore, further research is needed to take a clear picture of early childhood nutrition of left-behind children to allow policy-makers and health-care providers to optimize policy orientation and resource allocation for improvement of children' well-being, particularly in rural China, where $38.1 \%$ of children under 3 years old experience separation from one or both parents due to parental migration [2]. Secondly, most previous studies did not determine the impacts of different parental migration statuses on child nutrition. The limited evidence available suggests that maternal or both-parental migration may be more detrimental to child nutrition than paternal migration $[16,22]$.

In this study, we examined the association between various parental migration status and the nutrition of children aged 6-35 months in rural China using repeated cross-sectional data. This study will enhance our understanding of the nutritional status of left-behind children and the need for special interventions in early childhood and, by providing evidence for identifying health-related policy priorities, will enable the development of cost-effective interventions to improve the wellbeing of these vulnerable populations.

\section{Methods}

\section{Design and participants}

We used repeated cross-sectional data comprising two surveys conducted in six counties of northern and southern China in 2013 and 2016, respectively. The first survey was conducted prior to an early childhood development program in six countries of two provinces from July to September 2013: Songtao, Liping, and Pan Counties in Guizhou Province, and Fenxi, Lin, and Fangshan Counties in Shanxi Province [23]. In each county, a clustered random sampling method was used to select villages that met the following criteria: reachable by car from the county capital, with $\geq 50$ resident children under 3 years of age, and with a sufficient number of caregivers willing to participate in the survey. Finally, totals of 40 intervention villages and 43 control villages were included in the study. All children under 3 years old in these selected villages were eligible for participation in the survey. The second survey was conducted in the same villages from July to September 2016 by the same method, and the participants were another group of children under 3 years old at this survey time who were not included in the first survey. Finally, totals of 2953 and 2745 children under 3 years old were enrolled in 2013 and 2016, respectively. According to the number of eligible children $(n=4288)$ in 2013 , the response rate was $68.9 \%$ in 2013 and $64.0 \%$ in 2016 .

According to the research objective, our analysis did not include children under 6 months old (375 in 2013 and 335 in 2016) because they were not measured for hemoglobin $(\mathrm{Hb})$ concentration. Among children aged 6-35 months who were measured for at least one nutritional outcome (length, weight or hemoglobin concentration) (2560 in 2013 and 2398 in 2016), we also excluded twins, singleparent children, and those with serious diseases or disabilities (186 in 2013 and 125 in 2016). In addition, we did not include children with only migrant mothers because of the small number of such children (38 in 2013 and 63 in 2016). Finally, this present study only used data of 
children aged 6-35 months with available nutritional outcomes and with non-migrant parents (NLBC), migrant fathers (FLBC), or both migrant parents (PLBC).

\section{Measure}

Face-to-face interviews with caregivers were conducted by uniformly trained local health workers. Data were immediately input, saved, and transmitted to statisticians by means of an electronic questionnaire application, which had a basic logic and integrity-checking function to enable investigators to correct errors and supplement omissions in a timely manner.

\section{Basic characteristics}

The following sociodemographic characteristics of the children and their caregivers were collected: (a) child gender, age, preterm, and ethnicity; and (b) caregiver's relationship to the child, gender, age, and educational attainment. Depression among caregivers was measured using Zung's self-rating depression scale (ZSDS), which is validated and used worldwide and consists of 20 items representing depressive features with a total score ranging from 20 to 80 [24]. ZSDS was administered by trained interviewers, and a ZSDS score of $\geq 50$ was defined as depression. Household economic status was measured by the number of the following household electrical appliances and vehicles owned: telephone, washing machine, refrigerator, and TV in 2013; and telephone, washing machine, refrigerator, TV, motorcycle, tricycle, and car in 2016. Low household economic status was defined as owning fewer than three and four of these items in 2013 and 2016, respectively.

Some children in Songtao, Liping, Fenxi, and Lin counties received the interventions of the early childhood development program from 2014. Therefore, two variables related to the interventions were measured and controlled for as confounding factors in the analysis of the 2016 survey data. The first variable is the frequency of consumption of Yingyangbao supplements (a daily intake package of soybean-based micronutrient fortified powders), which was classified as: never supplemented, ever supplemented but none in the past week, 0-6 packages in the past week, and $\geq 7$ packages in the past week. The second is the frequency of nutritional consultations with health-care workers in the past 6 months, which was classified as: never, less than once per month, and one or more per month.

\section{Child breastfeeding and dietary intakes}

As recommended in Indicators for Assessing Infant and Young Child Feeding Practices by the World Health Organization (WHO) [25], a 24-h reported food recall was performed to assess breastfeeding and the dietary intake of the following seven food groups: (a) grains, roots and tubers, (b) legumes and nuts, (c) dairy products, (d) flesh foods (meat or fish), (e) eggs, (f) vitamin-A rich fruits and vegetables, and $(\mathrm{g})$ other fruits and vegetables. Then the following indicators were calculated: (1) ever being breastfed, (2) duration of breastfeeding (only for children weaned from breastfeeding), (3) meal frequency (frequency of dairy, solid, semi-solid, and soft food intake during the previous day), and (4) dietary diversity (number of food groups children consumed during the previous day).

\section{Nutritional outcomes}

The length, weight, and peripheral blood $\mathrm{Hb}$ concentration of the children were measured using standard procedures by uniformly trained health-care workers who were blinded to the above interview information. Children were weighed twice in light clothes without shoes using an electronic weight scale with $0.01 \mathrm{~kg}$ accuracy. Their recumbent, barefooted, and bareheaded lengths were measured twice using a standard infant length scale with $0.1 \mathrm{~cm}$ accuracy. A third measurement was performed if the two measurements differed by $1.0 \mathrm{~cm}$ or more for length and $0.5 \mathrm{~kg}$ or more for weight. The $\mathrm{Hb}$ concentration of the children was measured using HemoCue201+ (HemoCue AB Inc.). The length-for-age $Z$ score (LAZ), weight-for-age $Z$ score (WAZ), and weight-for-length $Z$ score (WLZ) were calculated according to the WHO Child Growth Standards and the corresponding score of $<-2$ was used to define stunting, underweight and wasting, respectively [26]. According to the $\mathrm{WHO}$ guidelines, $\mathrm{Hb}$ concentration was adjusted for altitude and children with an altitude-adjusted $\mathrm{Hb}$ concentration of $<11 \mathrm{~g} / \mathrm{dL}$ were considered to be anemic [27].

\section{Statistical analysis}

To double validate any associations and take into account the effect of time, we analyzed the data of the two time points independently. Univariate analysis was first conducted to compare the basic characteristics and nutritional outcomes according to parental migration status by $t$-test and Mann-Whitney $\mathrm{U}$ test for continuous variables and the chi-squared test for categorical variables.

Generalized linear regressions were performed to estimate the adjusted mean differences (aMDs) with 95\% confidence intervals (CIs) in LAZ, WAZ, and WLZ scores and Hb concentration according to parental migration status at each time point, after controlling for resident county, child gender, age, preterm and ethnicity in 2013, as well as additional two intervention variables in 2016. Household economic status and caregiver's relationship to the child, gender, age, and educational attainment were not controlled for because they were severely collinear with parental migration status and were strongly considered as mediators of the effects of parental migration on child nutrition. For categorical nutritional outcomes including stunting, underweight, wasting, and 
anemia, multivariate logistic regressions were employed to calculate the adjusted odds ratios (aORs) and 95\% CIs after controlling for the same covariates as above.

Similar multivariable adjusted analyses were also performed on $\mathrm{Hb}$ concentration and anemia for children aged 6-17 and 18-35 months, respectively, based on the result of the preliminary analysis that the differences in $\mathrm{Hb}$ concentration and the risk of anemia between children with different parental migration statuses varied before and after the age of 18 months.

Statistical analyses were performed using Statistical Package for the Social Sciences (SPSS) software 20.0 (SPSS, Inc., Chicago, IL). A two-tailed $p$-value of $<0.05$ was taken to reflect statistical significance.

\section{Results}

\section{Study population}

In total, 4546 children aged 6-35 months (2336 in 2013 and 2210 in 2016) were included in this study. They consisted of 1285 and 1089 NLBC, 819 and 784 FLBC, and 232 and 337 PLBC in 2013 and 2016, respectively.

The characteristics of the children are presented in Table 1. In 2013 and 2016, NLBC and FLBC had similar median ages (19-20 months) but were 2-4 months younger than PLBC. The distribution of child gender and preterm birth did not differ significantly according to parental migration status.

The characteristics of the caregivers were similar in the two surveys. NLBC and FLBC were primarily cared for by their mothers. Their median age was 26-27 years and about $70 \%$ of them were educated to a middle school or higher level. More than $95 \%$ of PLBC were cared for by their grandparents (median age of around 50 years), and less than one-third of the caregivers were educated to a middle school or higher level (21.5\% in 2013 and $31.1 \%$ in 2016). In 2013, the caregivers of PLBC had a significantly higher risk of depression than the caregivers of FLBC or $\operatorname{NLBC}(50.6 \%$ vs. 37.1 and $40.0 \%, p<0.05)$. The risk of

Table 1 Characteristics of the children and caregivers

\begin{tabular}{|c|c|c|c|c|c|c|}
\hline \multirow[t]{2}{*}{ Characteristics } & \multicolumn{3}{|l|}{2013 survey } & \multicolumn{3}{|l|}{2016 survey } \\
\hline & NLBC $(n=1285)$ & FLBC $(n=819)$ & $\mathrm{PLBC}(n=232)$ & $\overline{\operatorname{NLBC}}(n=1089)$ & FLBC $(n=784)$ & $\operatorname{PLBC}(n=337)$ \\
\hline \multicolumn{7}{|l|}{ Resident county, n (\%) } \\
\hline Lin & $181(14.1)$ & $110(13.4)^{+}$ & $14(6.0) \neq \S$ & $150(13.8)$ & $98(12.5)^{+}$ & $21(6.2) £ \S$ \\
\hline Fenxi & $157(12.2)$ & $242(29.5)$ & $7(3.0)$ & $113(10.4)$ & $239(30.5)$ & $71(21.1)$ \\
\hline Fangshan & $229(17.8)$ & $170(20.8)$ & $17(7.3)$ & $191(17.5)$ & $114(14.5)$ & $20(5.9)$ \\
\hline Songtao & $120(9.3)$ & $28(3.4)$ & $43(18.5)$ & $100(9.2)$ & $29(3.7)$ & $37(11.0)$ \\
\hline Liping & $100(7.8)$ & $74(9.0)$ & $110(47.4)$ & $109(10.0)$ & $87(11.1)$ & $76(22.6)$ \\
\hline Pan & $498(38.8)$ & $195(23.8)$ & $41(17.7)$ & $426(39.1)$ & $217(27.7)$ & $112(33.2)$ \\
\hline Boys, n (\%) & $727(56.6)$ & $467(57.0)$ & $121(52.2)$ & $601(55.2)$ & $440(56.1)$ & $169(50.1)$ \\
\hline Child age (months), median (25th, 75th) & $20(13,27)$ & $19(11,27)$ & $23(17,28) \neq \S$ & $20(12,27)$ & $20(12,27)$ & $22(18,29) \neq \S$ \\
\hline Preterm children, n (\%) & $39(3.0)$ & $24(2.9)$ & $2(0.9)$ & $54(5.0)$ & $47(6.0)$ & $11(3.3)$ \\
\hline Minority ethnic of children, $\mathrm{n}(\%)$ & $435(33.9)$ & $199(24.3)^{\dagger}$ & $167(72.0) \neq \S$ & $394(36.2)$ & $205(26.1)^{\dagger}$ & $163(48.4) \neq \S$ \\
\hline \multicolumn{7}{|l|}{ Relationship of caregivers to the child, $\mathrm{n}(\%)$} \\
\hline Parents & $1243(96.7)$ & $776(94.7)$ & $0(0.0)^{\ddagger \S}$ & $1048(96.2)$ & $733(93.5)^{+}$ & $0(0.0)^{\ddagger \S}$ \\
\hline Grandparents & $39(3.0)$ & $42(5.1)$ & $229(98.7)$ & $39(3.6)$ & $47(6.0)$ & $321(95.3)$ \\
\hline Others & $3(0.2)$ & $1(0.1)$ & $3(1.3)$ & $2(0.2)$ & $4(0.5)$ & $16(4.7)$ \\
\hline Female gender of caregiver, $\mathrm{n}(\%)$ & $1035(80.5)$ & $809(98.8)^{+}$ & $187(80.6)^{\S}$ & $938(86.1)$ & $762(97.2)^{+}$ & $279(82.8)^{\S}$ \\
\hline Caregiver age (years), median (25th, 75th) & $27(24,31)$ & $26(24,30)$ & $51(48,56) \neq \S$ & $27(24,32)$ & $27(24,31)$ & $52(47,56)^{\ddagger \S}$ \\
\hline \multicolumn{7}{|l|}{ Education attainment of caregivers, $\mathrm{n}(\%)$} \\
\hline High school or above & $165(12.9)$ & $123(15.0)$ & $8(3.4) \neq \S$ & $218(20.0)$ & $158(20.2)$ & $18(5.3) \nRightarrow \S$ \\
\hline Middle school & $694(54.0)$ & $462(56.4)$ & $42(18.1)$ & $560(51.4)$ & $423(54.0)$ & $87(25.8)$ \\
\hline Primary school & $343(26.7)$ & $186(22.7)$ & $66(28.4)$ & $249(22.9)$ & $162(20.7)$ & $104(30.9)$ \\
\hline Illiteracy & $83(6.5)$ & $48(5.9)$ & $116(50.0)$ & $62(5.7)$ & $41(5.2)$ & $128(38.0)$ \\
\hline Depression among caregivers ${ }^{a}, \mathrm{n}(\%)$ & $485(40.0)$ & $291(37.1)$ & $117(50.6) \neq \S$ & $388(35.9)$ & $249(31.8)$ & $128(38.0)^{\S}$ \\
\hline Low household economic status ${ }^{b}, \mathrm{n}(\%)$ & $180(14.0)$ & $79(9.6)^{+}$ & $44(19.0)^{\S}$ & $157(14.4)$ & $122(15.6)$ & $89(26.4)^{\neq \S}$ \\
\hline
\end{tabular}

$N L B C$ non-left-behind children, $F L B C$ left-behind children with migrant fathers, $P L B C$ left-behind children with both migrant parents

a 73 NLBC, 34 FLBC and 1 PLBC in 2013, and 9 NLBC and 2 FLBC in 2016 missed the information of depression among caregivers

${ }^{b} 1$ NLBC in 2013 and 1 FLBC in 2016 missed the information of household economic status

${ }^{+}$FLBC vs. NLBC $p<0.05 ;{ }^{\ddagger}$ PLBC vs. NLBC $p<0.05 ;{ }^{\S}$ PLBC vs. FLBC $p<0.05$ 
depression among the caregivers in 2016 was lower than that in 2013, and the prevalence of depression among the caregivers of NLBC, FLBC, and PLBC was 35.9, 31.8, and $38.0 \%$, respectively (Table 1 ).

FLBC had a higher household economic status than NLBC in 2013, but a similar one in 2016. PLBC had a lower household economic status than NLBC and FLBC in both 2013 and 2016 (Table 1).

\section{Stunting, underweight and wasting}

Table 2 shows the anthropometric outcomes of children with various parental migration statuses. From 2013 to 2016, the prevalence of stunting (NLBC: 19.0 to $13.4 \%$, by 29.5\%; FLBC: 11.8 to $8.9 \%$, by $24.6 \%$; PLBC: 18.6 to $15.4 \%$, by $17.2 \%$; Total: 16.4 to $12.1 \%, 26.2 \%$ ), underweight (NLBC: 9.2 to $4.3 \%$, by $53.3 \%$; FLBC: 6.5 to $4.0 \%$, by $38.5 \%$; PLBC: 12.1 to $3.0 \%$, by $75.2 \%$; Total: 8.5 to $4.0 \%$, by $52.9 \%$ ) and wasting (NLBC: 3.3 to $1.6 \%$, by $51.5 \%$; FLBC: 3.3 to $1.8 \%$, by $45.5 \%$; PLBC: 5.2 to $0.6 \%$, by $96.2 \%$; Total: 3.5 to $1.5 \%$, by $57.1 \%$ ) decreased in all groups of children. Greater reductions in the risks of underweight and wasting were found, especially among PLBC.
In 2013, the results of univariate analyses show that PLBC had significantly lower WAZ ( -0.77 vs. $-0.46, p<$ $0.01)$ and WLZ $(-0.24$ vs. $0.10, p<0.01)$ scores than NLBC, and also had significantly lower LAZ ( -1.07 vs. $-0.57, p<0.01)$, WAZ $(-0.77$ vs. $-0.19, p<0.01)$, and WLZ $(-0.24$ vs. $0.19, p<0.01)$ scores and higher risks of stunting $(18.6 \%$ vs. $11.8 \%, p<0.01)$ and underweight $(12.1 \%$ vs. $6.5 \%, p<0.01)$ than FLBC; however, these differences were not statistically significant after controlling for children's sociodemographic characteristics. In addition to the better performance in these anthropometric outcomes than PLBC aforementioned, FLBC were shown by univariate analyses to have significantly higher LAZ $(-0.57$ vs. $0.89, p<0.01)$ and WAZ $(-0.19$ vs. $-0.46, p<0.01)$ scores and lower risks of stunting $(11.8 \%$ vs. $19.0 \%, p<0.05)$ and underweight $(6.5 \%$ vs. $9.2 \%, p<0.05)$ than NLBC; even after controlling for children's sociodemographic characteristics, their differences in LAZ scores (aMD 0.13 [95\%CI: 0.01, 0.26]) and the risk of stunting (aOR 0.73 [95\%CI 0.56, 0.96]) were significant (Table 2).

In 2016, both univariate and multivariate analyses identified no significant differences in the anthropometric

Table 2 The anthropometric outcomes of children aged 6-35 months with various parental migration statuses

\begin{tabular}{|c|c|c|c|c|c|c|c|}
\hline & \multicolumn{4}{|c|}{ Outcomes [mean (SD)/n/N (\%)] ${ }^{a}$} & \multicolumn{3}{|c|}{ Adjusted differences [aMD (95\%Cl) / aOR (95\%Cl)] b } \\
\hline & NLBC & FLBC & PLBC & Total & FLBC vs. NLBC & PLBC vs. NLBC & PLBC vs. FLBC \\
\hline \multicolumn{8}{|l|}{2013} \\
\hline $\begin{array}{l}\text { Length/height-for-age } \\
\text { z-score }\end{array}$ & $-0.89(1.45)$ & $-0.57(1.33)^{\dagger}$ & $-1.07(1.25)^{\S}$ & $-0.80(1.40)$ & $0.13(0.01,0.26)$ & $0.08(-0.13,0.28)$ & $-0.02(-0.23,0.19)$ \\
\hline $\begin{array}{l}\text { Stunting }(<-2 z- \\
\text { scores) }\end{array}$ & 234/1231 (19.0\%) & $92 / 781(11.8 \%)^{+}$ & $42 / 226(18.6 \%)^{\S}$ & $368 / 2238(16.4 \%)$ & $0.73(0.56,0.96)$ & $0.79(0.53,1.19)$ & $1.08(0.70,1.68)$ \\
\hline Weight-for-age z-score & $-0.46(1.34)$ & $-0.19(1.24)^{\dagger}$ & $-0.77(1.29) \neq \S$ & $-0.40(1.31)$ & $0.11(-0.01,0.22)$ & $0.07(-0.12,0.25)$ & $-0.02(-0.22,0.18)$ \\
\hline $\begin{array}{l}\text { Underweight (<-2 } \\
z \text {-scores) }\end{array}$ & $114 / 1245(9.2 \%)$ & $52 / 797(6.5 \%)^{\dagger}$ & $28 / 232(12.1 \%)^{\S}$ & $194 / 2274(8.5 \%)$ & $0.77(0.54,1.09)$ & $1.14(0.69,1.87)$ & $1.49(0.86,2.55)$ \\
\hline $\begin{array}{l}\text { Weight-for-length/ } \\
\text { height z-score }\end{array}$ & $0.10(1.13)$ & $0.19(1.18)$ & $-0.24(1.15)^{\ddagger \S}$ & $0.09(1.16)$ & $0.02(-0.08,0.12)$ & $0.04(-0.13,0.21)$ & $0.03(-0.15,0.20)$ \\
\hline $\begin{array}{l}\text { Wasting }(<-2 z- \\
\text { scores) }\end{array}$ & 40/1222 (3.3\%) & 26/791 (3.3\%) & $12 / 229(5.2 \%)$ & $78 / 2242(3.5 \%)$ & $1.02(0.61,1.71)$ & $1.23(0.59,2.56)$ & $1.20(0.55,2.62)$ \\
\hline \multicolumn{8}{|l|}{2016} \\
\hline $\begin{array}{l}\text { Length/height-for-age } \\
\text { z-score }\end{array}$ & $-0.71(1.22)$ & $-0.61(1.12)$ & $-0.83(1.27)^{\S}$ & $-0.69(1.20)$ & $0.01(-0.09,0.12)$ & $0.06(-0.08,0.20)$ & $0.05(-0.09,0.19)$ \\
\hline $\begin{array}{l}\text { Stunting }(<-2 z- \\
\text { scores })\end{array}$ & $144 / 1078(13.4 \%)$ & $69 / 773(8.9 \%)^{+}$ & $51 / 332(15.4 \%)^{5}$ & $264 / 2183(12.1 \%)$ & $0.73(0.53,1.01)$ & $0.99(0.68,1.43)$ & $1.35(0.89,2.04)$ \\
\hline Weight-for-age z-score & $-0.31(1.05)$ & $-0.19(1.02)$ & $-0.32(1.00)^{\S}$ & $-0.27(1.03)$ & $0.02(-0.07,0.11)$ & $0.09(-0.03,0.21)$ & $0.07(-0.06,0.19)$ \\
\hline $\begin{array}{l}\text { Underweight ( }<-2 \\
z \text {-scores) }\end{array}$ & 47/1086 (4.3\%) & $31 / 783(4.0 \%)$ & 10/335 (3.0\%) & $88 / 2204$ (4.0\%) & $1.03(0.63,1.67)$ & $0.52(0.25,1.08)$ & $0.51(0.24,1.09)$ \\
\hline $\begin{array}{l}\text { Weight-for-length/ } \\
\text { height z-score }\end{array}$ & $0.10(0.96)$ & $0.18(1.03)$ & $0.15(0.88)$ & $0.14(0.97)$ & $0.02(-0.07,0.11)$ & $0.09(-0.03,0.21)$ & $0.08(-0.05,0.20)$ \\
\hline $\begin{array}{l}\text { Wasting }(<-2 z- \\
\text { scores) }\end{array}$ & 17/1073 (1.6\%) & 14/770 (1.8\%) & $2 / 328(0.6 \%)$ & $33 / 2171$ (1.5\%) & $1.28(0.61,2.65)$ & $0.38(0.09,1.73)$ & $0.30(0.07,1.38)$ \\
\hline
\end{tabular}

NLBC non-left-behind children, FLBC left-behind children with migrant fathers, PLBC left-behind children with both migrant parents, aMD adjusted mean difference, $a O R$ adjusted odds ratio

${ }^{a}$ The number of children with available outcomes was indicated with $N$ after slash

baMDs and aORs were adjusted for sociodemographic characteristics of children (resident county, child gender, age, preterm and ethnicity) in 2013,

and additional two intervention variables (the frequency of consumption of Yingyangbao supplements and the frequency of received nutritional

consultations) in 2016

${ }^{\dagger}$ FLBC vs. NLBC $p<0.05 ;{ }^{\ddagger}$ PLBC vs. NLBC $p<0.05 ;{ }^{\S}$ PLBC vs. FLBC $p<0.05$ 
outcomes between PLBC and NLBC. Although a lower risk of stunting $(8.9 \%$ vs. $13.4 \%, p<0.05)$ than NLBC and higher HAZ $(-0.83$ vs. $-0.61, p<0.05)$ and WAZ $(-0.32$ vs. $-0.19, p<0.05)$ scores than PLBC were found by univariate analyses among FLBC, no such differences were detected in the multivariable adjusted analyses (Table 2).

\section{Anemia}

Table 3 shows the $\mathrm{Hb}$ concentration and the prevalence of anemia among children with various parental migration statuses. $44.8 \%$ of children in 2013 and $43.8 \%$ of children in 2016 were identified with anemia. A lower risk of anemia and higher $\mathrm{Hb}$ concentration was found by univariate analyses among PLBC compared with NLBC and FLBC both in 2013 (34.9\% vs. 44.3 and $48.3 \% ; 11.29 \mathrm{~g} / \mathrm{dL}$ vs. $10.95 \mathrm{~g} / \mathrm{dL}$ and $10.85 \mathrm{~g} / \mathrm{dL})$ and $2016(35.2 \%$ vs. 45.0 and $45.9 \% ; 11.15 \mathrm{~g} /$ dL vs. $10.87 \mathrm{~g} / \mathrm{dL}$ and $10.80 \mathrm{~g} / \mathrm{dL}$ ). Multivariate logistic regressions reveal that the odds of anemia were significantly lower for PLBC than for FLBC (aOR 0.67 [95\%CI 0.47, 0.94]) in 2013, and than for NLBC (aOR 0.74 [95\%CI 0.56, 0.97]) and FLBC (aOR 0.75 [95\%CI 0.47, 0.56, 1.00]) in 2016.
Further, the results of stratified analysis for age group show that about one-third of children aged 18-35 months were anemic with no significant difference between children with different parental migration statuses (32.7\% of NLBC, $36.0 \%$ of FLBC, and $32.2 \%$ of PLBC in 2013 , and 29.8 , 35.8, and $32.9 \%$ in 2016, respectively). However, in the children aged 6-17 months, about twothirds of those living with mothers or both parents (61.5\% of NLBC and $63.6 \%$ of FLBC in 2013, and $66.2 \%$ of NLBC and $60.1 \%$ of FLBC in 2016) were identified with anemia, which was much higher than the corresponding proportion in those with both migrant parents (43.1\% in 2013 and $42.5 \%$ in 2016). Both univariate and multivariable adjusted analyses show that PLBC aged 617 months had a significantly higher $\mathrm{Hb}$ concentration and lower risk of anemia than NLBC and FLBC of the same age group in 2013 and 2016 (Table 3).

\section{Breastfeeding and dietary intake}

Child breastfeeding and dietary intake are presented in Fig. 1 . More than $85 \%$ of children were ever breastfed in

Table 3 Mean hemoglobin concentration and anemia prevalence among children aged 6-35 months with various parental migration statuses

\begin{tabular}{|c|c|c|c|c|c|c|c|}
\hline & \multicolumn{4}{|c|}{ Outcomes [mean (SD)/n/N (\%)] ${ }^{a}$} & \multicolumn{3}{|c|}{ Adjusted differences [aMD $(95 \% \mathrm{Cl}) / \mathrm{aOR}(95 \% \mathrm{Cl})]^{\mathrm{b}}$} \\
\hline & $\overline{N L B C}$ & FLBC & PLBC & Total & FLBC vs. NLBC & PLBC vs. NLBC & PLBC vs. FLBC \\
\hline \multicolumn{8}{|l|}{2013} \\
\hline \multicolumn{8}{|c|}{ Hemoglobin concentration $(\mathrm{g} / \mathrm{dL})$} \\
\hline $6-17$ months & $10.43(1.52)$ & $10.38(1.54)$ & $10.99(1.38)^{\neq 5}$ & $10.44(1.53)$ & $-0.08(-0.29,0.14)$ & $0.53(0.10,0.96)$ & $0.60(0.15,1.04)$ \\
\hline $\begin{array}{l}18-35 \\
\text { months }\end{array}$ & $11.30(1.18)$ & $11.23(1.43)$ & $11.38(1.48)$ & $11.29(1.30)$ & $-0.07(-0.22,0.09)$ & $0.05(-0.18,0.29)$ & $0.10(-0.15,0.35)$ \\
\hline Total & $10.95(1.39)$ & $10.85(1.54)$ & $11.29(1.46) \neq 5$ & $10.95(1.46)$ & $-0.08(-0.20,0.05)$ & $0.18(-0.03,0.39)$ & $0.24(0.02,0.46)$ \\
\hline \multicolumn{8}{|l|}{ Anemia } \\
\hline 6-17 months & $311 / 506(61.5 \%)$ & $229 / 360(63.6 \%)$ & $25 / 58(43.1 \%)^{\neq 5}$ & $565 / 924(61.1 \%)$ & $0.06(-0.18,0.30)$ & $0.75(0.35,1.15)$ & $0.71(0.29,1.12)$ \\
\hline $\begin{array}{l}18-35 \\
\text { months }\end{array}$ & $245 / 749(32.7 \%)$ & $160 / 445$ (36.0\%) & $55 / 171(32.2 \%)$ & 460/1365 (33.7\%) & $-0.07(-0.27,0.13)$ & $-0.12(-0.36,0.11)$ & $-0.10(-0.35,0.15)$ \\
\hline Total & $556 / 1255(44.3 \%)$ & 389/805 (48.3\%) & $80 / 229(34.9 \%)^{\ddagger 5}$ & $1025 / 2289(44.8 \%)$ & $1.17(0.96,1.41)$ & $0.78(0.56,1.08)$ & $0.67(0.47,0.94)$ \\
\hline \multicolumn{8}{|l|}{2016} \\
\hline \multicolumn{8}{|c|}{ Hemoglobin concentration ( $\mathrm{g} / \mathrm{dL}$ ) } \\
\hline 6-17 months & $10.27(1.59)$ & $10.32(1.88)$ & $11.10(1.04)^{\ddagger 5}$ & $10.36(1.68)$ & $1.13(0.84,1.52)$ & $0.47(0.27,0.85)$ & $0.42(0.23,0.76)$ \\
\hline $\begin{array}{l}18-35 \\
\text { months }\end{array}$ & $11.31(1.43)$ & $11.14(1.77)$ & $11.17(1.93)$ & $11.23(1.65)$ & $1.17(0.91,1.52)$ & $1.00(0.67,1.50)$ & $0.85(0.56,1.31)$ \\
\hline Total & $10.87(1.59)$ & $10.80(1.86)$ & $11.15(1.75)^{\neq \S}$ & $10.89(1.72)$ & $-0.01(-0.16,0.14)$ & $0.14(-0.06,0.34)$ & $0.12(-0.09,0.33)$ \\
\hline \multicolumn{8}{|l|}{ Anemia } \\
\hline 6-17 months & $299 / 452(66.2 \%)$ & $193 / 321(60.1 \%)$ & $34 / 80(42.5 \%))^{\neq 5}$ & $526 / 853(61.7 \%)$ & $0.80(0.58,1.09)$ & $0.39(0.23,0.65)$ & $0.49(0.29,0.82)$ \\
\hline $\begin{array}{l}18-35 \\
\text { months }\end{array}$ & $187 / 628(29.8 \%)$ & $161 / 450(35.8 \%)^{+}$ & $83 / 252(32.9 \%)$ & $431 / 1330(32.4 \%)$ & $1.17(0.89,1.53)$ & $1.00(0.72,1.39)$ & $0.86(0.61,1.21)$ \\
\hline Total & $486 / 1080(45.0 \%)$ & $354 / 771$ (45.9\%) & $117 / 332(35.2 \%) \neq 5$ & $957 / 2183(43.8 \%)$ & $0.99(0.80,1.21)$ & $0.74(0.56,0.97)$ & $0.75(0.56,1.00)$ \\
\hline
\end{tabular}

NLBC non-left-behind children, FLBC left-behind children with migrant fathers, PLBC left-behind children with both migrant parents, aMD adjusted mean difference, $a O R$ adjusted odds ratio

${ }^{\text {a } T h e ~ n u m b e r ~ o f ~ c h i l d r e n ~ w i t h ~ a v a i l a b l e ~ o u t c o m e s ~ w a s ~ i n d i c a t e d ~ w i t h ~} N$ after slash

baMDs and aORs were adjusted for sociodemographic characteristics of children (resident county, child gender, age, preterm and ethnicity) in 2013, and additional two intervention variables (the frequency of consumption of Yingyangbao supplements and the frequency of received nutritional consultations) in 2016

${ }^{\dagger}$ FLBC vs. NLBC $p<0.05 ;{ }^{\ddagger}$ PLBC vs. NLBC $p<0.05 ;{ }^{\S}$ PLBC vs. FLBC $p<0.05$ 
a
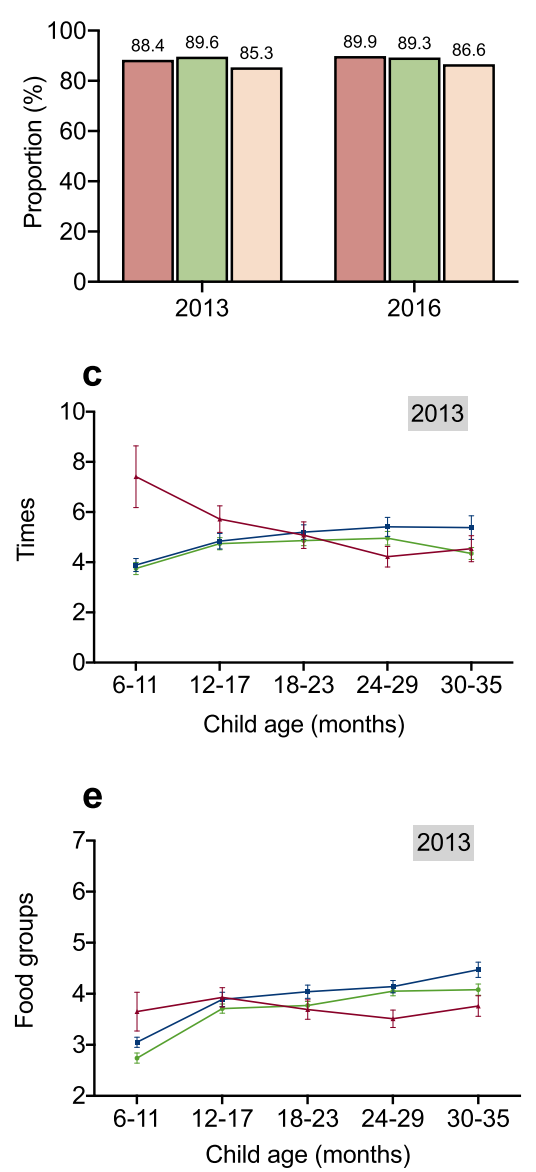

\section{b}
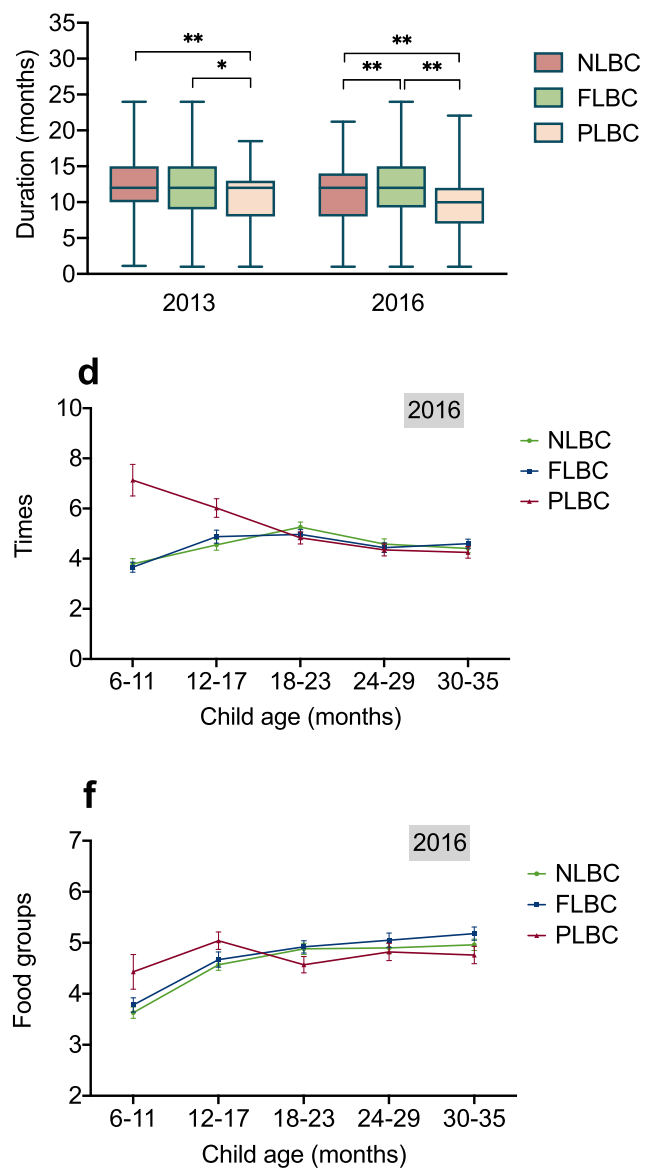

Fig. 1 Breastfeeding and dietary intake of children with different parental migration status. NLBC, non-left-behind children; FLBC, left-behind children with migrant fathers; PLBC, left-behind children with both migrant parents. a Bar chart of the proportion of ever being breastfed. $\mathbf{b}$ Boxplots of breastfeeding duration; the central line in each box indicates the median, and the bottom and top edges of the box indicate the 25th and 75th percentiles respectively; the top and bottom whiskers extend to the 2.5th and 97.5th percentiles. $\mathbf{c}$ and $\mathbf{d}$ Line chart of meal frequency. $\mathbf{e}$ and $\mathbf{f}$ Line chart of dietary diversity. The symbols and bars on the line chart indicate the mean and the standard error of mean, respectively

2013 and 2016, and the proportion was not significantly different between children with various parental migration statuses. PLBC had a shorter duration of breastfeeding than FLBC and NLBC (10.82 vs. 11.89 and 12.26 months in 2013, and 9.98 vs. 12.28 and 11.31 months in 2016). The median duration of breastfeeding in FLBC was similar to NLBC in 2013 but longer than NLBC in 2016. Children's dietary diversity increased from 2013 to 2016, irrespective of their parental migration status. In 2013, FLBC had slightly higher meal frequency and dietary diversity than NLBC, but in 2016, the differences were of lesser magnitude or absent. Compared with NLBC and FLBC, PLBC had higher meal frequency and dietary diversity at age of 6-17 months but slightly lower meal frequency and dietary diversity at age of 18-35 months.

\section{Discussion}

Early childhood nutrition is important as it lays the foundation for health in later life. In the context of rapid development and large-scale rural-to-urban migration in China, we evaluated the early childhood nutrition of rural left-behind children using the latest and reliable data. Our work not only extends the observations to children of younger age but also improves our understanding of the association between various parental migration statuses and child nutrition in the current social context.

The findings demonstrate the improvement of early childhood nutrition in recent years in rural China. The estimated risks of stunting, underweight, and wasting among rural infants and toddlers in 2013 in this study are consistent with previous reports during the similar 
period $[10,15,16]$. A study using the data of 6136 children aged $0-3$ years in central and western China during 2010-2011 showed that the prevalence of stunting among NLBC, FLBC, and PLBC was 16.4, 15.1, and $16.6 \%$, respectively [15]. A national survey of the nutritional status of rural left-behind children under 7 years old was conducted among 7585 left-behind children and 7557 non-left-behind children from 13 provinces of China during 2008-2009, and found that the prevalence of stunting among under-7-year-old children with nonmigrant, one, and both migrant parents was 16.3, 14.9, and $17.9 \%$, that of underweight was $7.6,7.2$, and $8.3 \%$, and the prevalence of wasting was $3.3,3.1$, and $3.4 \%$, respectively [16]. However, these estimates are lower than the corresponding values derived from our survey in 2016. In 2016, the estimated prevalence of stunting, underweight and wasting among surveyed children aged 6-35 months were $12.1,4.0$, and $1.5 \%$, respectively, which decreased by $26.2,52.9$, and $57.1 \%$ compared with 2013 , respectively, and are lower than other developing countries [19]. Child dietary diversity had also been greatly improved, irrespective of their parental migration status.

Consistent with previous estimates [10, 28, 29], this study also highlights the constantly and alarmingly high risk of anemia among children under 3 years old in rural China. The results show that about two-thirds of children aged 6-17 months and one-third of the children aged 1835 months were anemic, and no significant reduction of risk of anemia was found among these children from 2013 to 2016. Children aged 6-17 months with migrant parents had a significantly lower risk of anemia compared with those living with their mothers or with both parents, which may be attributed to earlier breastfeeding cessation and complementary feeding because of maternal migration. Despite the benefits of breastfeeding to child growth and development, prolonged breastfeeding was found to be associated with decreased dietary intakes and increased risk of anemia in infants and young children over 6 months of age [30-34]. This association was not significant at $\geq 18$ months of age when most children are weaned from breastfeeding irrespective of the parental migration status. The results also suggest the critical problem in complementary feeding among rural children. Most mothers and caregivers may not have good knowledge about and practices in breastfeeding and complementary feeding $[29,35]$.

The present study broadly supports the previous findings that parental migration was not significantly detrimental to child nutrition $[13,16,22,36]$ and even confirm the benefits of paternal migration on early childhood nutrition of rural children $[13,37,38]$, despite contrary results found in other studies [5, 18, 39]. A decreasing difference in early childhood nutrition between children with various parental migration statuses was shown in recent years, and in the survey in 2016, no significant differences in risks of stunting, underweight, and wasting were detected between them. Except for the obvious substitution of complementary foods for breast milk among children with migrant parents before 18 months of age, the difference in dietary intake among children with different parental migration statuses also decreased. However, it is worth noting that our findings do not mean that children in rural China are well-nourished or that left-behind children are not vulnerable. Despite the great reduction in the risk of macronutrient deficiency, all rural children were still at high risk of micronutrient deficiency such as anemia. In addition, a growing body of literature highlights the need for special attention to the negative effects of parental migration on children's cognitive and socialemotional development, especially when both parents migrate [40-42].

The mechanism by which parental migration affects child nutrition may be very complex. On the one hand, migration brings economic benefits, broadens the families' horizons and leads to new life perspectives, which is beneficial to the health of children by increasing health-related investment, improving left-behind caregivers' mental health, and substantially changed parenting attitude and practices [13, 22, 43, 44]. On the other hand, the absence of one or both parents can increase psychological stress among left-behind children as well as caregivers [45-49]; it can also reduce the time allocated to child care within households and even causes caregiver rearrangement and changed feeding practices when both parents migrate [50]. These two effects are working against one another, leading to the indeterminate net effect of migration on early childhood nutrition. In our study, FLBC had better household economic status than NLBC in 2013, which may partly account for the lower risk of undernutrition among FLBC; in 2016, they had similar household economic status, and the differences in the risk of undernutrition between them were also of lesser magnitude than those in 2013. However, we found families with migrant parents may be poorer than families with non-migrant parents or with migrant fathers only. This may imply a complex relationship between labor migration and family economics: migration of more family members brings more economic gains but also may indicate poorer family economics. Caregivers' education and depressive symptoms affect child nutrition mostly by affecting feeding practices [51-54]. In our study, compared to caregivers included in 2013, those included in 2016 had significantly higher levels of education and less depressive symptoms, which may partly explain the improvement of feeding practices and child nutrition during this period. Increasingly similar determinants between children with various parental migration statuses may also account for their 
decreasing differences in nutritional outcomes in recent years. It is worth noting that rural areas in China have developed rapidly in recent years, which may greatly contribute to the improvement of child nutrition. Overall, a variety of healthy foods are increasingly available in rural areas, and farmers are getting richer. Even with limited income, many farmers have improved water, hygiene and sanitation, and renovated their houses with the support of the government. Increasingly convenient transportation, mailing and communication technology also make it easier for migrant parents to participate in child feeding.

Our study has implications for the formulation of programs and policies to improve child health and development in rural China. The results show a high risk of anemia among rural children, regardless of parental migration status, suggesting a broad need for nutritional support for all rural children, especially prevention from micronutrient deficiency. Mothers are suggested to accompany their children in early childhood given the important health benefits of breastfeeding. Nutrition education and some micronutrient fortified foods can be provided to all caregivers. The Chinese government provides special social services for left-behind children as one of the goals of the National Program of Action for Child Development in China (2011-2020) [55]. However, our findings indicate that due to social and economic development, left-behind children may have equal or slightly better nutrition than non-left-behind children. Therefore, programs and policies designed to promote the well-being of left-behind children should pay more attention to other important issues such as cognitive and social-emotional development.

Our study has some strengths. Repeated cross-sectional data of two large-sample surveys in the same areas were used. In each survey, well-established and validated methods were employed to measure child nutritional status by investigators blinded to parental migration status and the basic characteristics of the children and their caregivers. However, several limitations also exist. First, the low response rate may bias the results. About $40 \%$ of the eligible children in the selected villages were not enrolled in the surveys. According to rough interviews with local coordinators, the reasons why the caregivers with their children did not participate in the surveys probably include being busy with household tasks, lack of interest or being not at home, etc. Second, we failed to measure some important factors that may moderate the effects of parental migration on the health of left-behind children, such as the number of siblings, migration duration, the age of children at the time of the first separation from migrant parents, migrant-caregiver communication, and remittances from migrants [36, 48, 56-58]. Third, the interventions of the early childhood development program may confound the analysis of the 2016 survey data, but we controlled for related variables in the regression analyses. Fourth, this study is also limited by its cross-sectional design, and the resulting associations need to be further demonstrated by longitudinal studies. Finally, the generalizability of the results is limited because all participants were from povertystricken rural areas of northern and southern China, and about half of them were from three counties of Guizhou Province where a large number of residents are of minorities. In addition, in rural China, many villages have less than 50 children under 3 years of age, which means the selected villages may not be that representative.

\section{Conclusions}

In conclusion, this study provides information on the changes over time of early childhood nutrition of leftbehind children in rural China, and provides new evidence that parental migration is no longer detrimental and even beneficial to the nutrition of these children but all the children are still at high risk of anemia. Although future programs for left-behind children should continue to focus on nutrition, they should also pay more attention to other important health issues such as mental health. Further research is needed to develop a clearer and full-scale picture of the impact of parental migration on the wellbeing of left-behind children of all ages.

\section{Abbreviations}

aMD: adjusted mean difference; aOR: adjusted odds ratio; FLBC: Left-behind children with migrant fathers; Hb: Hemoglobin; LAZ: Length-for-age Z score; LBC: Left-behind children; NLBC: Non-left-behind children; PLBC: Left-behind children with both migrant parents; WAZ: Weight-for-age Z score; WHO: World Health Organization; WLZ: Weight-for-length Z score; ZSDS: Zung's self-rating depression scale

\section{Acknowledgements}

The authors gratefully acknowledge the support of UNICEF, investigators, participants and local government officials.

\section{Authors' contributions}

HS conceptualized and designed the study and drafted the manuscript. JZ and XW contributed to the study design and the data collection. YD assisted with the analyses and the writing. $\mathrm{CZ}$ and $\mathrm{XH}$ contributed to the writing and revising. All authors reviewed the manuscript. All authors have read and approved the final manuscript.

\section{Funding}

The data collection of this study was supported by the United Nations Children's Fund (0860/A0/05/502 Health \& Nutrition Grant). The funder had no role in study design, data analysis, data interpretation, decision to publish, or preparation of the manuscript.

\section{Availability of data and materials}

The datasets used and/or analysed during the current study are available from the corresponding author on reasonable request.

\section{Ethics approval and consent to participate}

This study was conducted according to the guidelines laid down in the Declaration of Helsinki and all procedures involving research study participants were approved by the Ethics Review Board of Peking University (approval number IRB00001052-16034). Written informed consent was obtained from all caregivers before data collection. 


\section{Consent for publication}

Not applicable.

\section{Competing interests}

The authors declare that they have no competing interests.

\section{Author details}

'Department of Maternal and Child Health, School of Public Health, Peking University, 38 Xueyuan Road, Haidian District, Beijing 100191, China. ${ }^{2}$ Section of Health, Nutrition, and Water, Environment and Sanitation, UNICEF China, 12 Sanlitun Road, Chao Yang District, Beijing 100600, China.

Received: 18 August 2019 Accepted: 13 February 2020

Published online: 18 February 2020

\section{References}

1. International Organization for Migration. World migration report 2018. Geneva: International Organization for Migration; 2018.

2. National Bureau of Statistics of China, UNICEF China, UNFPA China: Population status of children in China in 2015: facts and figures 2017. https://www.unicef.cn/en/reports/population-status-children-china-2015. Accessed 21 Jan 2018.

3. Li C, Yang N, Zhang H. Investigation of physical development among leftbehind children in rural areas in western Hunan province. Chin Gen Pract. 2011;14(3C):1000-1002,1005

4. Mo X, Xu L, Luo H, Wang X, Zhang F, Tobe RG. Do different parenting patterns impact the health and physical growth of 'left-behind' preschoolaged children? A cross-sectional study in rural China. Eur J Pub Health. 26(1):18-23.

5. Ning M, Chang H-H. Migration decisions of parents and the nutrition intakes of children left at home in rural China. Agric Econ. 2013;59(10):467-77.

6. Tao S, Yu L, Gao W, Xue W. Food preferences, personality and parental rearing styles: analysis of factors influencing health of left-behind children. Qual Life Res. 2016;25(11):2921-9.

7. Tian X, Ding C, Shen C, Wang H. Does parental migration have negative impact on the growth of left-behind children?-new evidence from longitudinal data in rural China. Int J Environ Res Public Health. 2017;14(11):1308.

8. Zhang N, Becares $L$, Chandola T. Does the timing of parental migration matter for child growth? A life course study on left-behind children in rural China. BMC Public Health. 2015;15:966.

9. Zhang N, Becares $L$, Chandola T. A multilevel analysis of the relationship between parental migration and left-behind children's macronutrient intakes in rural China. Public Health Nutr. 2016;19(11):1913-27.

10. Chen $C$, He W, Wang Y, Deng L, Jia F. Nutritional status of children during and post-global economic crisis in China. Biomed Environ Sci. 2011;24(4):321-8.

11. Liu W, Li S, Gai R. Status and influencing factors of growth and development among rural left-behind preschool children in Shandong province. Chin J Public Health. 2015;31(5):628-31.

12. Lu S, Lin Y-T, Vikse JH, Huang C-C. Well-being of migrant and left-behind children in China: education, health, parenting, and personal values. Int J Soc Welf. 2016;25(1):58-68.

13. Mu R. Brauw ad: migration and young child nutrition: evidence from rural China. J Popul Econ. 2015;28(3):631-57.

14. Zhou C, Sylvia S, Zhang L, Luo R, Yi H, Liu C, Shi Y, Loyalka P, Chu J, Medina $A$, et al. China's left-behind children: impact of parental migration on health, nutrition, and educational outcomes. Health Aff. 2015;34(11):1964-71.

15. Ban L, Guo S, Scherpbier RW, Wang X, Zhou H, Tata L. Child feeding and stunting prevalence in left-behind children: a descriptive analysis of data from a central and western Chinese population. Int J Public Health. 2017; 62(1):143-51.

16. Mou J-S, Luo J-Y, Li Y-P, Shuai Z-R, Liu X-H. Study on the nutritional status and determinants among rural stranded children in China. Chin J Epidemiol. 2009:30(5):439-43.

17. Peng X-C, Luo J-Y, Yao K-B, Hu R-S, Du Q-Y, Zhu M-Y. The status on care and nutrition of 774 children staying in rural areas while parents were in towns. Chin J Epidemiol. 2008;29(9):860-4.

18. Fellmeth G, Rose-Clarke K, Zhao C, Busert LK, Zheng Y, Massazza A, Sonmez $H$, Eder B, Blewitt A, Lertgrai W, et al. Health impacts of parental migration on left-behind children and adolescents: a systematic review and metaanalysis. Lancet. 2018;392(10164):2567-82.
19. Black RE, Allen LH, Bhutta ZA, Caulfield LE, de Onis M, Ezzati M, Mathers $C$, Rivera J. Maternal and child undernutrition: global and regional exposures and health consequences. Lancet. 2008;371(9608):243-60.

20. Victora CG, Adair L, Fall C, Hallal PC, Martorell R, Richter L, Sachdev HS. Maternal and child undernutrition: consequences for adult health and human capital. Lancet. 2008:371(9609):340-57.

21. Bhutta ZA, Ahmed T, Black RE, Cousens S, Dewey K, Giugliani E, Haider BA, Kirkwood B, Morris SS, Sachdev HP, et al. What works? Interventions for maternal and child undernutrition and survival. Lancet. 2008;371(9610):417-40.

22. Guo $Q$, Sun $W$, Wang Y. Effect of parental migration on children's health in rural China. Rev Dev Econ. 2017;21(4):1132-57.

23. Zhou S, Zhao C, Huang X, Li Z, Ye R, Shi H, Zhao Q, Zhou Y, Chen X, O'Sullivan $\mathrm{M}$, et al. The effect of a community-based, integrated and nurturing care intervention on early childhood development in rural China. Public Health. 2019;167(2019):125-35.

24. Zung WW. A self-rating depression scale. Arch Gen Psychiatry. 1965;12:63-70.

25. WHO, UNICEF, USAID, AED, UCDAVIS, IFPRI. Indicators for assessing infant and young child feeding practices part 2: measurement. Geneva: World Health Organization; 2010

26. WHO Multicentre Growth Reference Study Group. WHO child growth standards: length/height-for-age, weight-for-age, weight-for-length, weightfor-height and body mass index-for-age: methods and development. Geneva: World Health Organization; 2006.

27. WHO. Haemoglobin concentrations for the diagnosis of anaemia and assessment of severity. Geneva: Vitamin and Mineral Nutrition Information System. Geneva: World Health Organization (WHO/NMH/NHD/MNM/11.1); 2011.

28. Xin $Q$, Chen B, Yin D, Xiao F, Li R, Yin T, Yang H, Zheng X, Wang L. Prevalence of anemia and its risk factors among children under 36 months old in China. J Trop Pediatr. 2017;63(1):36-42.

29. Yue A, Marsh L, Zhou H, Medina A, Luo R, Shi Y, Zhang L, Kenny K, Rozelle $S$. Nutritional deficiencies, the absence of information and caregiver shortcomings: a qualitative analysis of infant feeding practices in rural China. PLoS One. 2016;11(4):e0153385.

30. Dalili H, Baghersalimi A, Dalili S, Pakdaman F, Hassanzadeh Rad A, Abbasi Kakroodi M, Rezvany SM, Koohmanaei S. Is there any relation between duration of breastfeeding and anemia? Iran J Ped Hematol Oncol. 2015;5(4):218-26.

31. Pasricha SR, Black J, Muthayya S, Shet A, Bhat V, Nagaraj S, Prashanth NS, Sudarshan $\mathrm{H}$, Biggs BA, Shet AS. Determinants of anemia among young children in rural India. Pediatrics. 2010;126(1):e140-9.

32. Torsvik IK, Markestad T, Ueland PM, Nilsen RM, Midttun O, Bjorke Monsen AL. Evaluating iron status and the risk of anemia in young infants using erythrocyte parameters. Pediatr Res. 2013;73(2):214-20.

33. Wang F, Liu H, Wan Y, Li J, Chen Y, Zheng J, Huang T, Li D. Prolonged exclusive breastfeeding duration is positively associated with risk of anemia in infants aged 12 months. J Nutr. 2016;146(9):1707-13.

34. Hipgrave DB, Fu X, Zhou H, Jin Y, Wang X, Chang S, Scherpbier RW, Wang $Y$, Guo S. Poor complementary feeding practices and high anaemia prevalence among infants and young children in rural central and western China. Eur J Clin Nutr. 2014;68(8):916-24.

35. Duan $Y$, Yang Z, Lai J, Yu D, Chang S, Pang $X$, Jiang S, Zhang H, Bi Y, Wang $J$, et al. Exclusive breastfeeding rate and complementary feeding indicators in China: a national representative survey in 2013. Nutrients. 2018;10(2):249.

36. Islam MM, Khan MN, Mondal MNI. Does parental migration have any impact on nutritional disorders among left-behind children in Bangladesh? Public Health Nutr. 2019;22(1):95-103.

37. Peng $X$, Luo J. Status and influencing factors of growth and development among rural left-behind children in Hunan province. China Public Health. 2013;29(1):34-7.

38. Zhongshuai L, Qun S. Parental non-agricultural employment and child health: evidence from rural China. Popul Econ. 2014;3:51-8.

39. Davis J, Brazil N. Migration, remittances and nutrition outcomes of leftbehind children: a national-level quantitative assessment of Guatemala. PLoS One. 2016;11(3):e0152089.

40. Cuong Viet N. Does parental migration really benefit left-behind children? Comparative evidence from Ethiopia, India, Peru and Vietnam. Soc Sci Med. 2016;153:230-9.

41. Yue A, Sylvia S, Bai Y, Shi Y, Luo R, Rozelle S. The effect of maternal migration on early childhood development in rural China; 2016. https://doi. org/10.2139/ssrn.2890108. Accessed 7 Dec 2018

42. Yue A, Shi Y, Luo R, Wang B, Weber A, Medina A, Kotb S, Rozelle S. Stimulation and early child development in China: caregiving at arm's length. J Dev Behav Pediatr. 2019;40(6):458-67. 
43. de Brauw A. Migration and child development during the food price crisis in El Salvador. Food Policy. 2011;36(1):28-40.

44. Toyota M, Yeoh BSA, Nguyen L. Bringing the 'left behind' back into view in Asia: a framework for understanding the 'migration-left behind nexus'. Popul Space Place. 2007;13(3):157-61.

45. Chen F, Liu H, Vikram K, Guo Y. For better or worse: the health implications of marriage separation due to migration in rural China. Demography. 2015; 52(4):1321-43.

46. Song Q. Aging and separation from children: the health implications of adult migration for elderly parents in rural China. Demogr Res. 2017;37:1761-92.

47. Graham E, Jordan LP, Yeoh BSA. Parental migration and the mental health of those who stay behind to care for children in South-East Asia. Soc Sci Med. 2015;132(2015):225-35.

48. Lu Y, Yeung JW-J, Liu J, Treiman DJ. Migration and children's psychosocial development in China: when and why migration matters. Soc Sci Res. 2019; 77(2019):130-47.

49. Thapa DK, Visentin D, Kornhaber R, Cleary M. Migration of adult children and mental health of older parents 'left behind': an integrative review. PLoS One. 2018;13(10):e0205665.

50. Chang H, Dong X-Y, Macphail F. Labor migration and time use patterns of the left-behind children and elderly in rural China. World Dev. 2011;39(12):2199-210

51. Guldan GS, Zeitlin MF, Beiser AS, Super CM, Gershoff SN, Datta S. Maternal education and child feeding practices in rural Bangladesh. Soc Sci Med. 1993;36(7):925-35.

52. Saxton J, Carnell S, Van Jaarsveld CHM, Wardle J. Maternal education is associated with feeding style. J Am Diet Assoc. 2009;109(5):894-8.

53. Hurley KM, Black MM, Papas MA, Canfield LE. Maternal symptoms of stress, depression, and anxiety are related to nonresponsive feeding styles in a statewide sample of WIC participants. J Nutr. 2008;138(4):799-805.

54. Dennis C-L, McQueen K. The relationship between infant-feeding outcomes and postpartum depression: a qualitative systematic review. Pediatrics. 2009; 123(4):E736-51.

55. The State Council of China. The national program of action for child development in China (2011-2020). http://www.nwccw.gov.cn/201705/12/content_155807.htm. Accessed 12 Jan 2018.

56. Sun X, Tian Y, Zhang Y, Xie X, Heath MA, Zhou Z. Psychological development and educational problems of left-behind children in rural China. Sch Psychol Int. 2015;36(3):227-52.

57. Wang L, Mesman J. Child development in the face of rural-to-urban migration in China: a meta-analytic review. Perspect Psychol Sci. 2015;10(6):813-31.

58. Hu S, Tan H, Peng A, Jiang H, Wu J, Guo S, Qian X. Disparity of anemia prevalence and associated factors among rural to urban migrant and the local children under two years old: a population based cross-sectional study in Pinghu, China. BMC Public Health. 2014;14:601.

\section{Publisher's Note}

Springer Nature remains neutral with regard to jurisdictional claims in published maps and institutional affiliations.

Ready to submit your research? Choose BMC and benefit from:

- fast, convenient online submission

- thorough peer review by experienced researchers in your field

- rapid publication on acceptance

- support for research data, including large and complex data types

- gold Open Access which fosters wider collaboration and increased citations

- maximum visibility for your research: over $100 \mathrm{M}$ website views per year

At $\mathrm{BMC}$, research is always in progress.

Learn more biomedcentral.com/submissions 